\title{
(6) OPEN ACCESS \\ Surgery in the time of Ebola: how events impacted on a single surgical institution in Sierra Leone
}

\author{
Ibrahim Bundu, ${ }^{1}$ A Patel, ${ }^{2}$ A Mansaray, ${ }^{1}$ T B Kamara, ${ }^{1}$ L M Hunt ${ }^{2}$
}

${ }^{1}$ Department of Surgery, Connaught Hospital, Freetown, Sierra Leone

${ }^{2}$ King's Sierra Leone Partnership, King's Centre for Global Health, London, UK

\section{Correspondence to} L M Hunt, Department of General Surgery, 1st Floor of Old Nurses Home, Northern General Hospital, Sheffield S5 7AU, UK; Lesley.Hunt@sth.nhs.uk

Received 10 November 2015 Revised 18 December 2015 Accepted 19 December 2015 Published Online First 19 January 2016

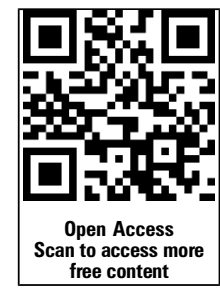

\begin{abstract}
Introduction The mortality and morbidity of Ebola extends far wider than those contracting the disease. Surgical activity in Sierra Leone has been severely disrupted by the epidemic.
\end{abstract}

Method This is a retrospective study examining the effect of the 2014-2015 Ebola virus epidemic on surgical activity in a Sierra Leone's main teaching hospital.

Results The impact of national and local events on surgical provision is illustrated by the experience of Connaught Hospital, Freetown Sierra Leone. Surgical activity fell dramatically in August 2014, the month when the most health care workers died and continued to fall to just $3 \%$ of expected activity. Two of eight surgeons at Connaught Hospital died of Ebola.

Discussion The example of Connaught Hospital serves as a graphic and poignant illustration of the difficulties faced by surgeons in low resource settings when dealing with the acute effects of a natural disaster. In any future epidemic, high levels of preparedness, training and protection, in addition to liaison with public health teams early in an epidemic, may allow surgeons to carry out at least some of their duties without the very high levels of personal risk seen here.

In a country with so few specialists the loss of $25 \%$ is disastrous and will result in long term capacity reduction.

\section{INTRODUCTION}

A decade-long civil war in the 1990s left Sierra Leone's healthcare system in ruins, with key healthcare indicators among the worst in the world. ${ }^{1}$ In 2009 , there were just 10 practicing surgeons in the 23 government hospitals, serving a population of 5.8 million people. ${ }^{2}$ Over the 5 -year period before the current Ebola virus disease (EVD) epidemic, the numbers of surgically trained staff impoved ${ }^{3}$ with 70 staff providing surgical care. However, many lack post graduate surgical qualifications or formal surgical training and they continue to endure severe shortages in infrastructure, personnel and supplies, including necessities such as electricity and oxygen.

EVD is a highly contagious viral haemorrhagic fever (VHF) spread by contact with bodily fluids and is often fatal. First described in Zaire in 1976 there have been seven major and many smaller reported natural outbreaks affecting between 1 and 425 people. Although retrospective investigation now suggests that it was smouldering for up to 3 months prior, the current epidemic, the largest in history, officially began in Guinea in March 2014 and spread rapidly to neighbouring Liberia and Sierra Leone (Figure 1), which has had the highest

\section{Key messages}

- The mortality and morbidity of Ebola virus disease extends beyond those infected with the virus and impacts on surgical and obstetric practice.

- $25 \%$ of the surgeons at Sierra Leone's only tertiary referral hospital (Connaught Hospital) died of Ebola.

- In any future epidemic, high levels of preparedness may allow more surgery to continue.

- In a country with so few surgeons the loss of $25 \%$ will result in long-term capacity reduction.

number of confirmed cases and EVD deaths (8704 and 3955 , respectively). ${ }^{4}$

The mode of transmission of EVD makes healthcare workers particularly vulnerable and many of the deaths have occurred in occupationally exposed healthcare workers. The rate of infection was thought to be more than double that in the general population. $^{5}$ A subsequent preliminary WHO report has indicated that across the three countries healthcare workers were 21-32 times more likely to be infected. ${ }^{6}$ By December 2014, 199 of Sierra Leone's $2402(8 \%)$ recorded healthcare workers had already died of Ebola ${ }^{5}$ and this was thought to be an underestimate as certain groups such as community health officers (CHOs) were not reliably recorded as healthcare workers. Exposure to untriaged patients outside of Ebola holding units (EHU) and treatment centres (ETC) represented a particular danger as a result of lack of personal protective equipment (PPE) and potentially unsafe patient flow pathways with infected patients ending up in clinical areas unsuited to their care. Many local staff contracted the disease in the course of their normal duties or through compassionate care in the community, and investigations into deaths of healthcare workers highlighted that non-adherence to referral pathways and triage greatly increased the risk of transmission. ${ }^{6}$

The symptoms of EVD (Table 1) overlap those of acute abdominal pathology, making it difficult to differentiate from many surgical illnesses, which often present with fever, abdominal pain and gastrointestinal disturbance. ${ }^{7}$ Across Sierra Leone surgical and obstetric admissions fell by $70 \%$ at the start of the epidemic and major operations by $50 \%$. By detailing the effect of the 2014-2015 Ebola virus epidemic on a single surgical institution, the reasons for the loss of surgical provision can be 


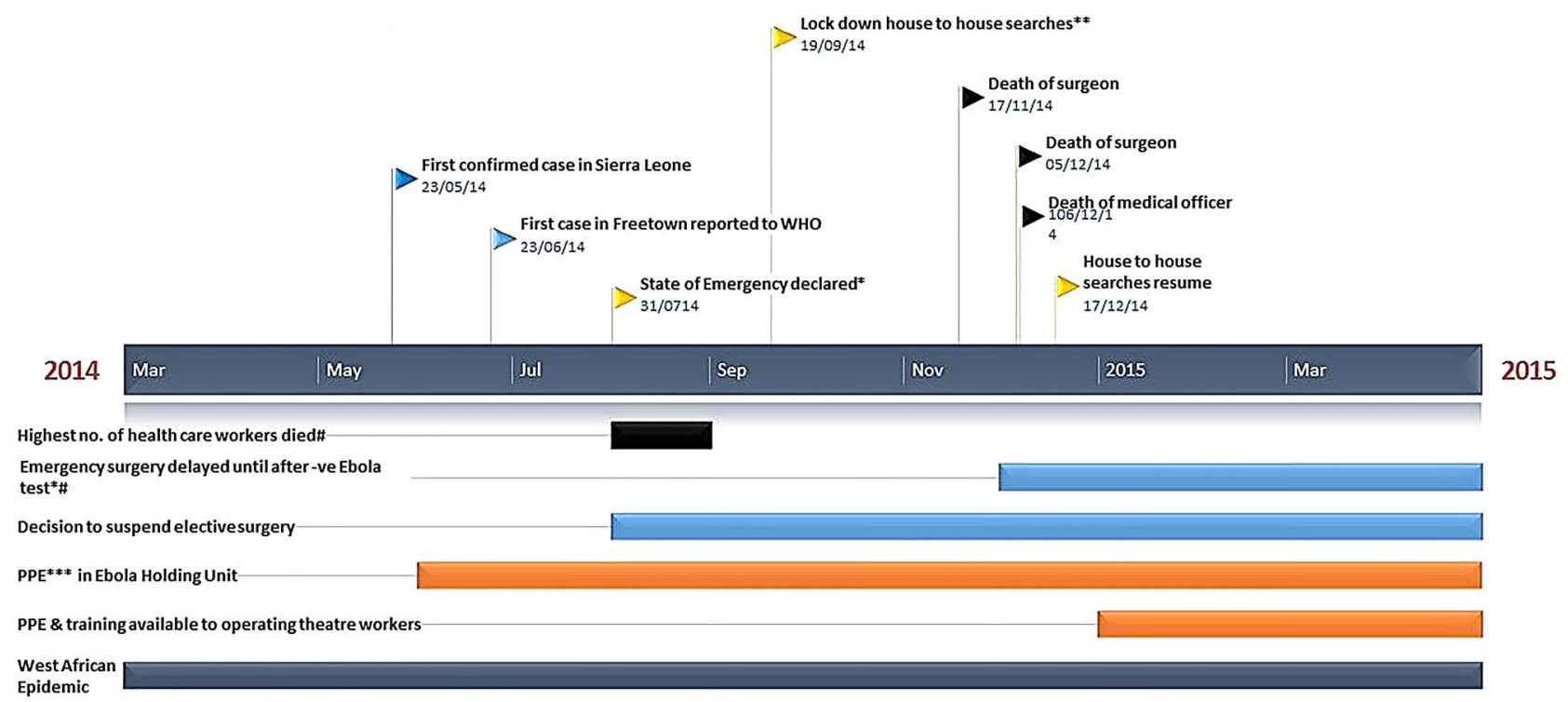

Figure 1 Timeline of national and local Ebola-related events. *A pass was required for all passengers and all vehicles to cross regional boundaries. Many could not obtain the passes. With no adequate ambulance service, the sick in Sierra Leone travel to hospital by public transport. Sick or febrile patients were denied access and not allowed to cross roadblocks. ** The searches brought patients to hospital and the fear of being discovered led some to self-refer beforehand. "Healthcare workers were stigmatised, found travel difficult and were afraid to come to work. There were industrial disputes about hazard payments to staff. ${ }^{* \#}$ The time to receive Ebola test results reduced during the epidemic from 3-4 days to 12 days on average. Patients with acute surgical conditions who met the Ebola case definition were nursed in the Ebola Holding Unit during this period. ${ }^{* *} \mathrm{PPE}$, personal protective equipment.

more fully understood and lessons can be learnt, which may reduce the impact in future epidemics.

\section{METHOD}

Connaught Hospital, in the capital Freetown, is government-run and Sierra Leone's main teaching hospital. It serves a local population of 2 million and is also a national referral centre for more complex surgeries, such as that arising from surgical complications and delayed presentations. These result in pathology, which would be considered gross by UK standards. At the start of the EVD epidemic, Connaught employed eight surgeons, covering all specialities, supported by eight surgical house officers and three surgical officers who are CHOs trained to perform emergency surgery.

Data on admissions to the emergency unit with surgical conditions, to the surgical wards and operative procedures over the time period 1 year preceding and during the EVD epidemic, were retrospectively collected during January to March 2015 by two authors (AP and AM) from multiple prospectively kept written sources, within the hospital to ensure reliability. Admission data were derived from accident and emergency (A\&E) records, surgical wards, EHU records, patient notes, staff interviews and nursing handover sheets, and the operation data

\section{Table 1 Symptoms of Ebola ${ }^{7}$}

Any person with sudden onset of high fever and inexplicable bleeding or at least three of the following symptoms

\begin{tabular}{ll}
\hline Headaches & Vomiting \\
Anorexia & Diarrhoea \\
Lethargy & Stomach pains \\
Aching muscles/joints & Difficulty swallowing \\
Breathing difficulty & Hiccup \\
\hline
\end{tabular}

were obtained from surgeons', anaesthetists' and operating theatre nurses' logs. All operations were included. A surgical presentation was one that was referred to the surgical team with a view to likely surgery. Data were collected manually and transferred to Excel spreadsheet for analysis.

\section{RESULTS}

The timeline of significant Ebola-related issues (Figure 1) indicates the chronology of events that impacted on Connaught Hospital and the decisions that were taken about surgical practice during the epidemic. In West Africa, there is seasonal change in surgical presentation for conditions as diverse as infections and trauma. ${ }^{8} 9$ In August 2014, A\&E presentations and ward admissions had fallen to approximately half the corresponding 2013 level (A\&E 120 vs 51; ward admissions 100 vs 51) and even further by December 2014: A\&E admissions fell from 115 to $42(37 \%)$ and ward admissions from 147 to 23 (16\%) (Figure 2). During this time Connaught Hospital's tertiary referral practice ceased.

The three sources of operative surgery data all show the same pattern and although no source was complete the variance was $<4 \%$ (Figure 3). In August 2014, operative surgery fell to $19 \%$ of its 2013 level. Surgical diagnosis was difficult as a lack of PPE and training required a no-touch policy outside of the Ebola Unit. After the deaths of the surgeons and the decision to postpone emergency surgery until after an Ebola test, operations fell to 3\% of their 2013 level. No patient operated on at Connaught Hospital subsequently died of Ebola.

At that time, Connaught Hospital was inundated with confirmed and suspected EVD cases, but stayed open when many hospitals were forced to close. An EHU was established in conjunction with King's Sierra Leone Partnership, from where patients were transferred to local ETC if Ebola was confirmed, or to the general wards if negative. The work of the EHU provided protection to hospital staff and allowed some non-Ebola activity to continue. However, working conditions were far 


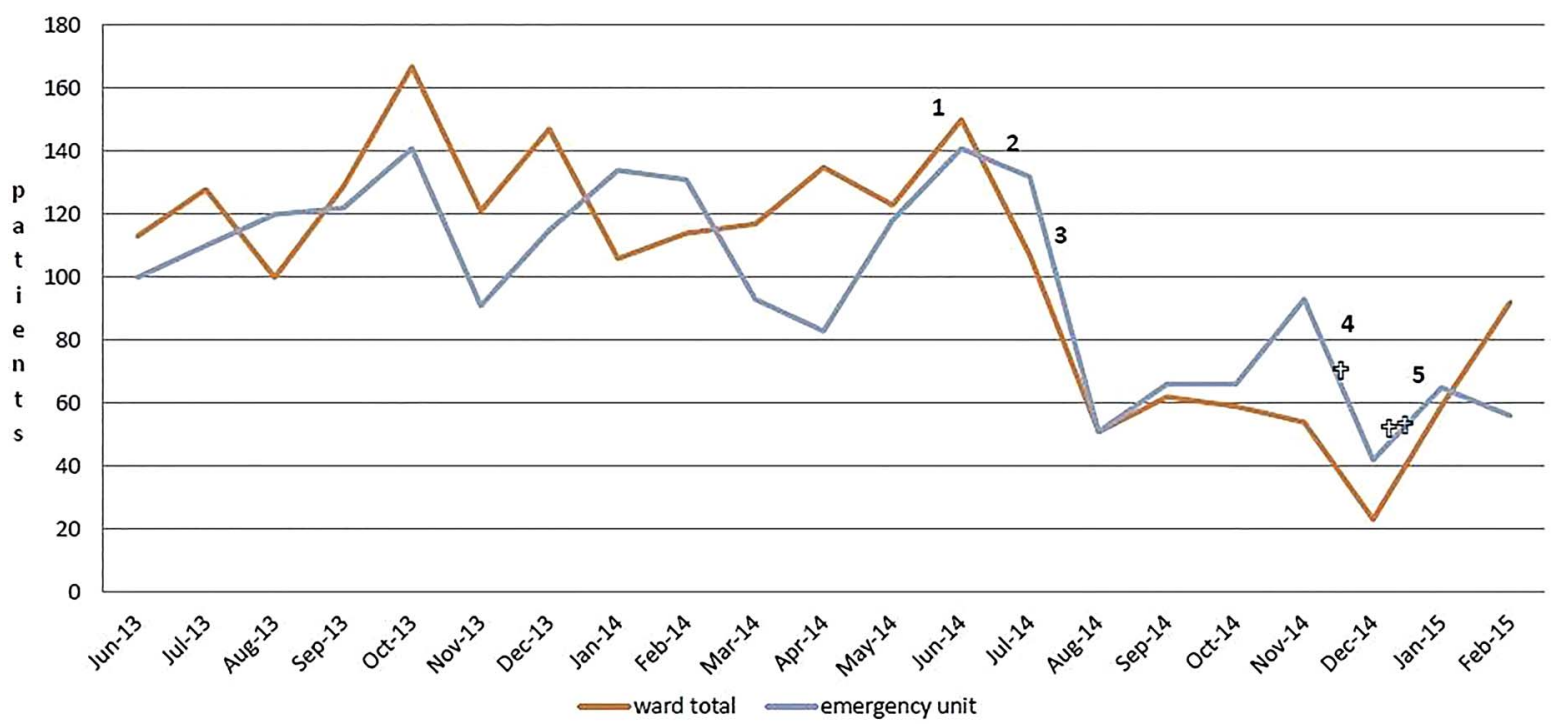

Figure 2 Surgical presentations at Connaught from June 2013 to February 2015. Key: 1. 23 May. First confirmed case in Sierra Leone. 2. 23 June. First confirmed case in Freetown. 3. August. Highest number of healthcare worker deaths and local decision to stop elective surgery. 4. December. Local decision to delay emergency abdominal surgery until after -ve Ebola test. 5. January full personal protective equipment made available to surgical team. tIndicates death of surgical doctor from Ebola.

from ideal and the outpatient department was closed after the surgeon's deaths following pressure from staff about safety.

\section{DISCUSSION}

A limitation of this study is its retrospective nature. Medical record keeping in low-resource settings is challenging, ${ }^{10}$ so to ensure reliability, data presented here were obtained from multiple sources.

A reduction in surgical and obstetric admissions has been observed across Sierra Leone during the epidemic. ${ }^{11}$ Connaught's admission rate dropped more than most and this was thought to be due to case mix. It has a large tertiary referral practice, which effectively ceased, and does not provide obstetric services that are included in the national figures.

The reasons for reduced patient presentation are multifactorial. There was certainly mutual distrust between patients and doctors. Factors include the fear of Ebola itself, fear of healthcare workers and what would happen to them at the hospital and the fear of being stigmatised. Ironically the fear factor surrounding epidemics has been studied in more depth in the USA population than in Africa ${ }^{12}$ where balancing risk and conveying uncertainty proved impossible even in the highly educated US population.

For patients still wishing to come to hospital, transport was not easy, particularly for tertiary referrals, and even on arrival things were difficult. Connaught Hospital experienced huge numbers of potential Ebola cases, all of whom had to be screened for the disease before entering the hospital. Screening was essential to prevent cases being admitted across the hospital with catastrophic consequences. Queues were inevitable and some of those who died during the process likely had surgical pathology. Before the Ebola epidemic the system for reporting

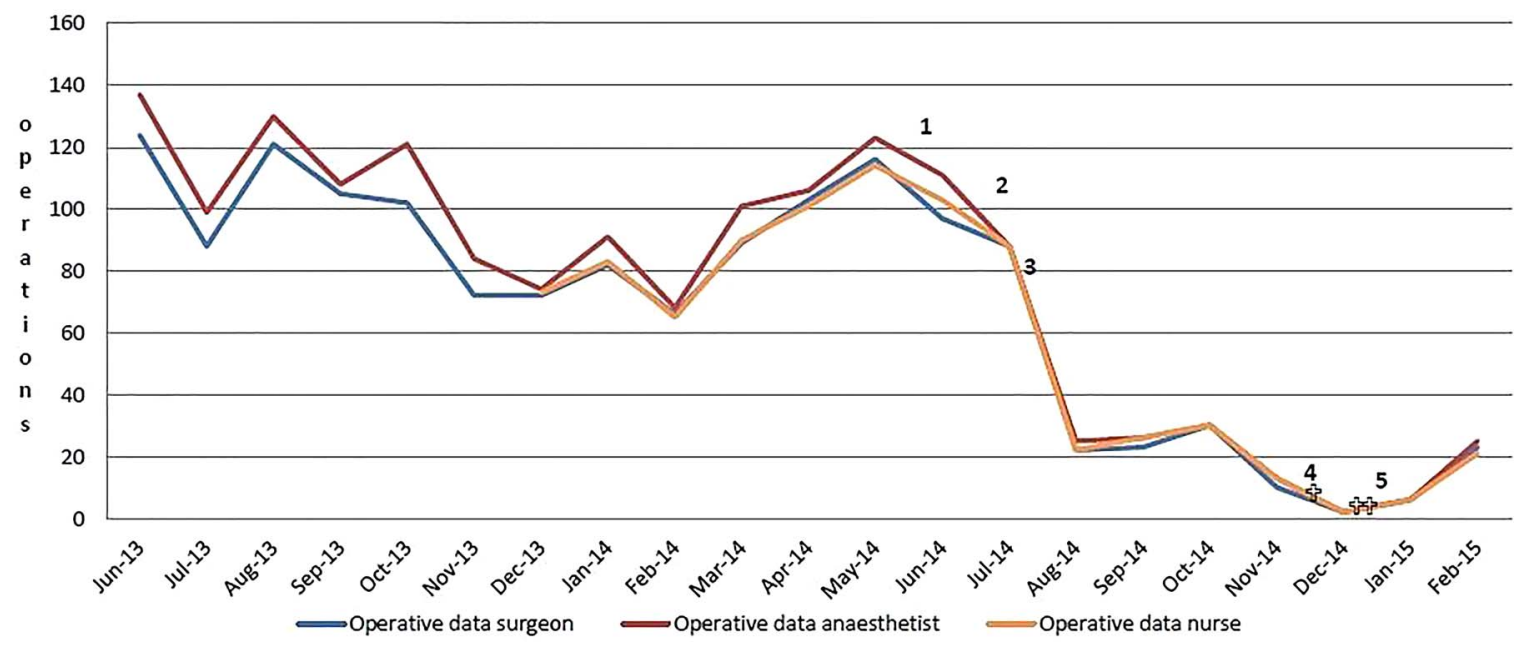

Figure 3 Operative surgery at Connaught from June 2013 to February 2015. Key: 1. 23 May. First confirmed case in Sierra Leone. 2. 23 June. First confirmed case in Freetown. 3. August. Highest number of healthcare worker deaths and local decision to stop elective surgery. 4. December. Local decision to delay emergency abdominal surgery until after -ve Ebola test. 5. January full personal protective equipment made available to surgical team. tIndicates death of surgical doctor from Ebola. 
Figure 4 Closed surgical ward at Masanga Hospital Sierra Leone.

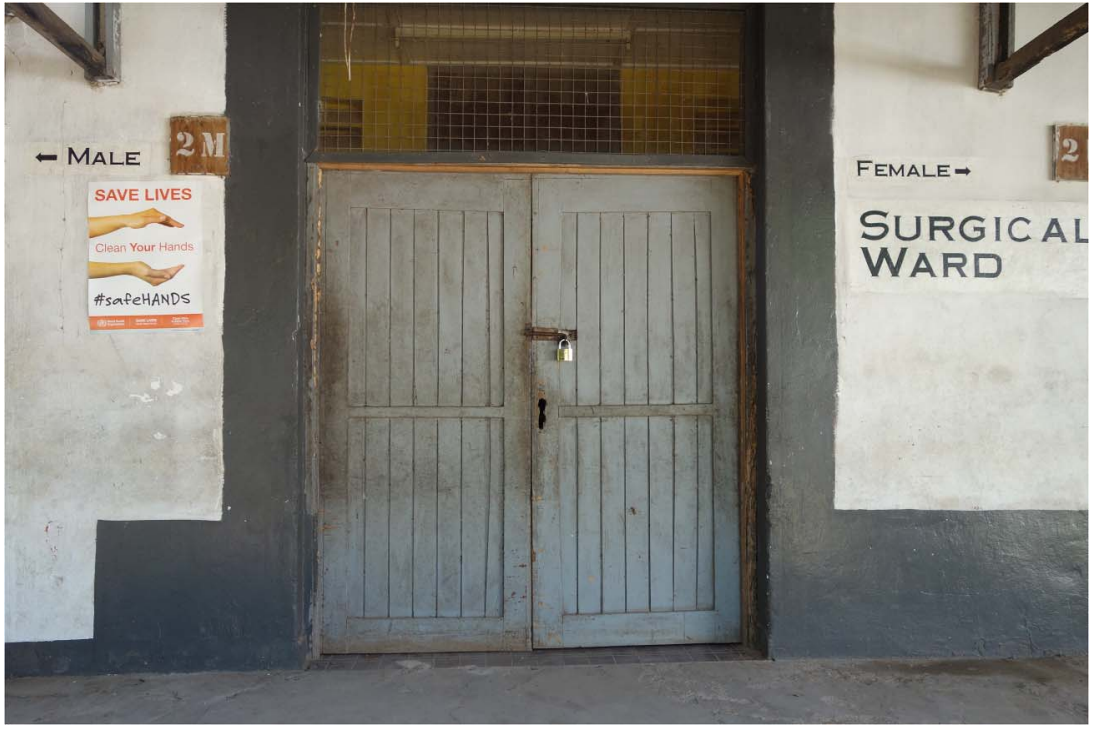

births and deaths in Sierra Leone was rudimentary, with as few as $1 \%-2 \%$ of all deaths being reported to the Vital Statistics office. The concept of a medically issued death certificate is not established, so there is considerable uncertainty about the cause of most non-Ebola deaths during the epidemic. ${ }^{13}$

As in the UK, not all admissions under surgeons result in an operation. Initially during the epidemic the impact on admissions was great but the percentage of patients being operated remained stable. However, after the deaths of the surgeons and before the provision of PPE and PPE training in the operating theatre this changed reaching just 3\% of the previous year's figure (Figures 2 and 3). After the deaths of the three surgeons the pressure on surviving colleagues was indescribable. There has never before been an epidemic of this kind. The surgeons were without adequate facilities to see their patients and without the equipment and training required to protect themselves and their teams. Patients found their way through holes in triage systems and although the speed of Ebola triage and testing improved as resources came into the country, during much of the epidemic it was not sufficient to separate those with surgical conditions from those with Ebola.

The public health impact of Ebola extends much further than the measured morbidity and mortality of the disease itself. Our study is of small size, but a variation of the events seen at Connaught was played out in hospitals across Sierra Leone. ${ }^{11}$ Over 6 million people had minimal access to surgical care for life-threatening illness (Figure 4). Maternity provision in West Africa was also badly hit ${ }^{14}$ and the United Nations Population Fund estimated that $15 \%$ of women giving birth in 2015 in Sierra Leone, Liberia and Guinea would die of obstetric complications as a result of loss of maternity provision. ${ }^{15}$

In any future VHF epidemics surgical provision will almost certainly suffer again. Rapid diagnosis of VHF and improvements in health infrastructure ${ }^{16}$ will have the most impact. However, future strategies can learn from the experience of the surgical team at Connaught Hospital, with the aim of minimising the reduction in lifesaving surgery and protecting the surgical team from unacceptable risk.

As Ebola control improves, the immediate results of the epidemic on surgery in Sierra Leone will lessen. However, in a country with so few surgeons, the loss of a few key individuals will have implications for many years and the repercussions of Ebola in Sierra Leone will continue long after the disease has been controlled.

\section{CONCLUSIONS}

This study has generated several key lessons that will need to be considered in any future VHF epidemic. There must be mandatory screening for VHF before any patient reaches the surgical team with a strict safe referral practice that cannot be bypassed. Surgical teams must assess patients in designated facilities and they must be trained in infection control and prevention, before future epidemics occur implying a significant training requirement. It will be essential to ensure the availability of adequate PPE to surgical teams and mandatory training for its effectiveness as easy as possible in an epidemic and finally the need to accept a period of conservative treatment for surgical patients whose symptoms overlap the case definition until a negative VHF test has been obtained.

Acknowledgements Dr Colin Brown, Dr Marta Lado Castro-Rial and Dr Dan Youkee for advice and manuscript review and our thanks go to the surgeons and staff of Connaught Hospital, Freetown.

Dedication We dedicate this paper to the memories of Dr TT Rogers, Dr Martin Salia and Dr Dauda Koroma who died of Ebola while serving their patients.

Contributors IB instigated this study and organised the data collection process. He has made a major contribution to the manuscript preparation. AP was responsible for much of the data collection, particularly those cases passing through the holding unit. He has contributed to the manuscript preparation and data analysis. AM was responsible for much of the data collection, particularly those cases in the surgical wards. He has contributed to the manuscript preparation. TBK was personally involved in many of the events described in this publication, facilitated much of the work and contributed to the manuscript preparation. LMH supervised the data collection and wrote the original manuscript. The sources used are as described in the manuscript and PubMed.

Funding AP and LMH declare support by way of travel and subsistence from King's Sierra Leone Partnership, King's Centre for Global Health.

\section{Competing interests None declared.}

Provenance and peer review Not commissioned; externally peer reviewed.

Open Access This is an Open Access article distributed in accordance with the Creative Commons Attribution Non Commercial (CC BY-NC 4.0) license, which permits others to distribute, remix, adapt, build upon this work non-commercially, and license their derivative works on different terms, provided the original work is properly cited and the use is non-commercial. See: http://creativecommons.org/ licenses/by-nc/4.0/

\section{REFERENCES}

1 http://www.unicef.org/infobycountry/sierraleone_statistics.htlm

2 Kingham TB, Kamara TB, Cherian MN et al. Quantifying surgical capacity in Sierra Leone: a guide for improving surgical care. Arch Surg 2009;144:122-7.

3 Vaughan E, Sesay F, Chima A et al. An assessment of surgery and anaesthesia staff at 10 government hospitals in Sierra Leone. JAMA Surg 2015;150:237-44. 
4 http://apps.who.int/ebola/current-situation/ebola-situation-report-7-october-2015

5 Kilmarx PH, Clarke KR, Dietz PM et al. Ebola virus disease in health care workers in Sierra Leone 2014. MMWR Morb Mortal Wkly Rep 2014;63:1168-71.

6 http://www.who.int/hrh/documents/21may2015_web_final.pdf

7 Case Definition recommendations for Ebola or Marburg virus disease. August 2014. http://www.who.int/ebola/ebolacasedefintion

8 de Villiers FPR, Sawyerr TN, de Villiers GK. The incidence and clinical presentation of infantile rotavirus diarrhoea in Sierra Leone. S Afr Med J 2009:99:249-52.

9 Bickler SW, Sanno-Duanda B. Epidemiology of paediatric trauma admissions to a government referral hospital in The Gambia. Bull WHO 2000;78:1330-6.

10 Landry A, Pett C, Fiorentino R. Assessing the quality of record keeping for caesarean section: results from a multicenter retrospective record review in five low-income countries. BMc Pregnancy Childbirth 2014;14:139.
11 Bolkan HA, Bash-Taqi DA, Samai M, et al. Ebola and indirect effects on health service function in Sierra Leone. PLoS Curr 2014;6.

12 Rosenbaum L. Communicating uncertainty-ebola, public health, and the scientific process. N Engl J Med 2015;372:7-9.

13 African Health Observatory. 2014. http://www.aho.afro.who.int/profiles_information/ index.php/Sierra_Leone:Civil_registration_and_vital_statistics_systems

14 Delamou A, Hammonds RM, Caluwaerts $S$ et al. Ebola in Africa: beyond epidemics, reproductive health in crisis. Lancet 2014;384:2105.

15 UNFPA Ebola wiping out gains in safe motherhood. http://www.unfpa.org/news/ ebola-wiping-out-gains-safe-motherhoodwww.who/int/csr.../publications

16 Fasina FO, Shittu A, Lazarus D et al. Transmission dynamics and control of ebola virus disease outbreak in Nigeria, July to September 2014. Euro Surveill 2014;19:20920. 